\title{
HIGIENISMO E EDUCAÇÃO ESCOLAR NA CIDADE DA PARAHYBA DURANTE A PRIMEIRA REPÚBLICA
}

\author{
Carlos Augusto de Amorim Cardoso \\ Eliana Alda de Freitas Calado \\ Nirvana Ligia Albino Rafael de Sá
}

\section{Resumo}

Este artigo tem como principal objetivo discutir de que modo o discurso higienista se fez presente na educação escolar da cidade da Parahyba no período da Primeira República, em especial no que se refere ao conhecimento geográfico da cidade. Entende-se que o debate higiênico nas escolas, bem como a criação de cadeiras de higiene, contribuíram para uma reinvenção da cidade por meio do paradigma do moderno. Para tanto, a pesquisa vem sendo realizada a partir dos estudos e procedimentos metodológicos da Geografia Histórica, através de documentos históricos, primários e secundários, que possam contribuir com o estudo histórico do espaço.

Palavras-chave: higienismo; educação escolar; cidade da parahyba.

\section{HYGIENISM AND SCHOOL EDUCATION IN THE CITY OF PARAHYBA DURING THE FIRST REPUBLIC}

\section{Abstract}

This article has as its main objective to discuss how the hygienist discourse was present in the school education of the City of Parahyba in the period of the First Republic, especially in the regard to the geographic knowledge of the city. It is understood that the hygiene debate in schools, as well as the creation of hygiene chairs, contributed to a reinvention of the city through the modern paradigm. To this end, the research has been carried out from the studies and methodological procedures of Historical Geography, through historical documents, from both primary and secondary sources, that can contribute to the histor3ical study of space.

Keywords: hygienism; school education; city of parahyba.

\section{HIGIENISMO Y EDUCACIÓN ESCOLAR EN LA CIUDAD DE PARAHYBA DURANTE LA PRIMERA REPÚBLICA}

\section{Resumen}

Este artículo tiene como objetivo principal discutir cómo el discurso higienista estuvo presente en la educación escolar de la ciudad de Parahyba en el período de la Primera República, especialmente con respecto al conocimiento geográfico de la ciudad. Se entiende que el debate sobre la higiene en las escuelas, así como la creación de clases de higiene, contribuyeron a una reinvención de la ciudad a través del paradigma de lo moderno. Con este fin, la investigación se ha llevado a cabo a partir de los estudios y procedimientos metodológicos de Geografía Histórica, a través de documentos históricos, primarios y secundarios, que pueden contribuir al estudio histórico del espacio.

Palabras clave: higienismo; educación escolar; ciudad de parahyba. 


\section{INTRODUÇÃO}

Neste texto, tem-se como principal objetivo discutir de que modo o discurso higienista se fez presente na educação escolar da Cidade da Parahyba no período da Primeira República, em especial no que se refere ao conhecimento geográfico da cidade. Entende-se que o debate higiênico nas escolas, bem como a criação de cadeiras de higiene, contribuiu para uma reinvenção da cidade "[...] através do paradigma de moderno delineado no Brasil em finais do século XIX e início do século XX" (CARDOSO, KULESZA, 2008, p. 02). Para tanto, a pesquisa vem sendo realizada a partir dos estudos e procedimentos metodológicos da Geografia Histórica, “[...] termo usado para identificar uma sub-disciplina aparentemente distinta das geografias acadêmicas que busca a espacialização dos fenômenos do passado, com a finalidade de entender e identificar as transformações que levaram à realidade atual" (GREGORY, 1991, p. 156), através de documentos históricos, primários e secundários, que possam contribuir com o estudo histórico do espaço.

Os pesquisadores que trabalham com a Geografia Histórica tendem a utilizar-se de ferramentas filosóficas e de metodologias que abrangem tanto a área da História quanto da Geografia. Para Philo (1996, p. 270), faz-se importante que a maneira de olhar do geógrafo e sua análise do espaço "[...] seja introduzida no estudo de todos esses fenômenos do passado [...] que são a própria substância da história e que atraíram a atenção dos historiadores (como também a de outros estudiosos das ciências sociais e das humanidades)".

Os documentos históricos utilizados constituem fontes primárias passíveis de serem empregadas pelos pesquisadores, de um modo geral. Configuram-se enquanto evidências de tempos idos, produzidas quando o fato histórico que se está pesquisando ocorria e utilizadas hoje para reconstruí-lo. Esses documentos vêm sendo utilizados a fim de entendermos como se dava a (re)produção do espaço urbano na cidade, as repercussões do ideário sanitarista sobre o mesmo, bem como a implantação de equipamentos urbanos ligados a esta busca por sanear e/ou modernizar os espaços.

Quanto à utilização dos documentos históricos, existe atualmente uma consonância entre historiadores e demais cientistas sociais - a exemplo de sociólogos, geógrafos, pedagogos, entre outros - que realizam pesquisas históricas, de que as fontes primárias podem ou não ser escritas, sendo explicitadas das mais diversas formas e tipos: cartas, documentos registrados em cartórios, diários, objetos, edificações, testemunhos orais, etc. Para este trabalho, priorizamos a utilização de documentos históricos escritos, oficiais e não oficiais, além de algumas fotografias e cartografia que retratam a cidade no período analisado e que servirão para ilustrar melhor o espaço que será tratado ao longo desta análise.

A reconstrução de espaços em tempos passados assemelha-se a um trabalho de "detetive", já que vivenciamos uma busca constante por dados que evidenciem essas áreas e que nos deem a possibilidade de investigar sua trama física. Para essa tarefa ser cumprida, deve-se recorrer a elementos econômicos, habitacionais e sociais expostos através dos documentos históricos que possam contribuir com o estudo histórico do espaço.

A partir da visita a esses arquivos, podemos dizer que os textos encontrados nas "instituições de memória" (NORA, 1984), e que guardam as publicações do período, expressam tanto o cotidiano da população como a tentativa de manutenção do que se entendia por "ordem" pela elite, já que era por essa forma de divulgação que as ações dominantes eram expressas, com o intuito, muitas vezes, de impulsionar hábitos e até mesmo direcionar a opinião pública.

Tratando sobre a utilização de documentos, Le Goff (1996, p. 535) expressa o seguinte: "[...] o que sobrevive não é aquilo que existiu no passado, mas uma escolha efetuada quer pelas 
forças que operam no desenvolvimento temporal do mundo e da humanidade, quer pelos que se dedicam à ciência do passado e do tempo". O autor enfatiza que, dentre os documentos encontrados, o pesquisador deve "escolher" aquele que mais se adequar ao seu objeto de pesquisa, a fim de analisá-lo e interpretá-lo, ou seja, cabe ao pesquisador retirar destas fontes as informações possíveis, mantendo-se “[...] o mais próximo possível dos textos” (LE GOFF, 1996, p. 536).

Ao tentarmos entender como os documentos foram utilizados em pesquisas históricas, percebemos que, ao final do século XIX, houve uma modificação de perspectiva em relação aos conteúdos extraídos desses documentos. Constatamos uma abrangência maior no tratamento das fontes históricas e, consequentemente, uma riqueza maior nos detalhes do objeto abordado. É neste momento que as pesquisas acerca do tempo recorrem também a outras fontes, como a memória oral, sons, imagens, fósseis, instrumentos de luta utilizados pela comunidade, fazendo com que a história pudesse ser reescrita com tudo que a habilidade do pesquisador, os arquivos, as instituições de memória (ABREU, 1988) que estão ao seu alcance, permitisse. Sobre isso, o autor afirma que é primordial lembrar que o resgate da memória das cidades "[...] não pode se limitar à recuperação das formas materiais de outros tempos. Há que se tentar dar conta daquilo que não deixou marcas na paisagem, mas que pode ainda ser recuperado nas instituições de memória" (ABREU, 1988, p. 86).

Não é evidente, portanto, levantar, investigar e compreender as marcas do Higienismo material e imaterialmente. Tentaremos, todavia, oferecer um olhar possível e fundamentado, iniciando a discussão pela historicização do Higienismo, em especial, do processo de adaptação deste ideário no contexto brasileiro e paraibano.

\section{O HIGIENISMO NO BRASIL E NA PARAHYBA}

A questão higiênica e o Higienismo chegam ao Brasil no século XIX como o "[...] ideário de um seleto grupo de intelectuais liderados pela classe médica" (BARRETO, 2010, p. 51). Tinha como meta a adoção de regras e práticas de higiene por parte da população por meio de medidas coercitivas e disciplinatórias tanto do corpo humano quanto do espaço urbano: "[...] higienizar, modernizar e civilizar a nação. Essas eram palavras de ordem que os 'homens de ciências' e os intelectuais engajados no projeto republicano proferiam, nomeando-se assim porta-vozes da corrente transformadora do país" (BARRETO, 2010, p. 54).

A institucionalização do saber médico foi uma das bases de fortalecimento do ideário político nacionalista. Em 1832, foram criadas as primeiras Faculdades de Medicina, na Bahia e no Rio de Janeiro, que seguiam fielmente as orientações dos higienistas franceses (MARIANO, 2015, p. 23). De acordo com a tese da pesquisadora Nayana Mariano (2015, p. 63-64), “[...] a medicina apresentou-se, nesse processo, como um caminho no almejado projeto civilizatório, tendo como meta proporcionar à nação a construção de uma civilização sadia”.

A ênfase política e social na questão higiênica também foi manifestada por meio da elaboração, nesta mesma época, de trabalhos chamados geografias e/ou topografias médicas, definidas como um conjunto de estudos de cunho geográfico e com base em dados estatísticos que apontam uma série de considerações a respeito da:

[...] origen y desarrollo de la mortalidad en general. Estas monografías médicas suelen ceñirse a ciudad, localidades y comarcas o regiones concretas, y tienen como base determinadas concepciones médicas, que consideran la génesis y evolución de las enfermedades como fuertemente determinadas por el clima y el medio local (URTEAGA, 1980, p. 07). 
As topografias médicas, a partir do discurso higiênico, consideravam tanto o meio natural como o meio social. Também refletem uma preocupação no que diz respeito à forma como estes poderiam contribuir para o desenvolvimento de enfermidades. Este fato levou a que os higienistas em geral promovessem críticas enfáticas à falta de salubridade das cidades e, principalmente, das habitações pobres, as quais, por não terem recursos, não podiam atentar para as determinações higiênicas propostas pelas elites. Cabiam às topografias, então, não apenas descrever minuciosamente as condições deste ambiente, como também propor medidas de caráter higiênico e social, para contribuir com uma melhoria na qualidade de vida, na saúde e na higiene da população considerada perigosa.

Trata-se, portanto, do momento em que a medicina se torna social e que a "[...] saúde da população deixa de significar unicamente a luta contra a doença para se tornar o correlato de um modelo médico-político de controle contínuo" (MACHADO, 1978, p. 53), a cidade torna-se alvo de transformações e a saúde passa a ser entendida como justificativa para isto. É exatamente pela modificação do controle sobre as doenças e percepção de que suas causas estão centradas não no próprio corpo, mas no espaço habitado, que a busca por salubridade se desloca do indivíduo para o espaço urbano.

De maneira geral, o período situado entre as últimas décadas do século XIX e as três primeiras do século XX corresponde a um momento importante para a história do Brasil por incluir diversos processos, acontecimentos e fenômenos, com largo impacto social. Destacamos, entre eles, a abolição da escravatura; o fim do Império e a implantação da República; uma fase de várias reformas importantes à educação (NAGLE, 2001), o início da fase da industrialização brasileira e, ainda, em decorrência destes processos, um crescimento urbano notável (COSTA, 1999). Mesmo que as cidades tenham sido afetadas por estes fenômenos em níveis e escalas diferenciadas, é inegável o fato de que o conjunto urbano brasileiro passou, a partir daí, por uma série de transformações, que podem ser observadas ao longo de todo o século XX. Constata-se neste tempo, de forma mais sistemática do que anteriormente, a busca por salubridade. Assim, este tema, pode ser entendido como "[...] talvez, o denominador mais comum das cidades brasileiras nessa época” (ABREU, 2001, p. 2), já que foi com base nos levantamentos e diagnósticos dos índices de salubridade que as cidades tiveram seus espaços urbanos "[...] avaliados, criticados, repensados; muitos deles transformados" (ABREU, 2001, p. 2).

Há, de forma visível, um discurso atribuído às cidades, posto nos relatórios dos governadores, nos periódicos, nas escolas, nos livros didáticos e na literatura de um modo geral. Um discurso higiênico que, muitas vezes está atrelado aos conhecimentos da Geografia e à Teoria dos Miasmas (MASTROMAURO, 2011). A Teoria dos Miasmas defendia que as doenças seriam transmitidas pelos ares de uma atmosfera contaminada por estarem concentradas nos ambientes, principalmente naqueles habitados pela população de menor poder aquisitivo. Por conseguinte, além do fortalecimento do preconceito social, justificavam-se as intervenções autoritárias e o afastamento desta população considerada "perigosa" dos lugares habitados pela "boa gente". Ou seja, por não possuírem ainda os meios científicos e técnicos suficientes à descoberta da influência causal dos micróbios, das bactérias e dos vírus, as autoridades médicas não apenas acreditavam como também difundiam a ideia de as doenças seriam transmitidas através de um ambiente onde o ar estaria contaminado pelos "odores" (emanações) da sujeira dos pântanos, das ruas e dos corpos - tanto dos vivos como dos mortos. Tais discursos, mesmo que nem sempre tenham sido efetivados, revelam certo ideal de uma cidade que, para ser considerada moderna, deveria ser higiênica e bela. 
Segundo Clementino Fraga (1930), escritor, médico e político, responsável pela chefia da campanha contra a febre amarela na capital, sempre que um domicílio urbano se tornava foco de infecção deveria ocorrer a vigilância médica, que se dirigia além do local de residência do doente até o estabelecimento laboral ou mesmo o local frequentado cotidianamente. Era então demarcado um raio de 250 a 300 metros no entorno das áreas consideradas focos, as quais deveriam ser desinfetadas por meio de visitas diárias, realizadas em um primeiro período por enfermeiras de saúde pública e, a partir de 1929, por médicos contratados pelo Departamento de Saúde. Assim que os casos eram identificados, passava-se a um controle mais direto com uma estimativa de que cada caso de doença fosse atendido por uma equipe composta por dez profissionais. Sendo cada um deles responsável por cerca "de 100 a 120 pavimentos", uma tarefa considerada árdua que seria diminuída naturalmente à medida que "[...] se via de muito facilitado o trabalho, à proporção que se familiarizavam os vigilantes com os moradores e lhes vinha, prestimosamente, a sua cooperação, encurtando as demoras" (FRAGA, 1930, s/p).

No entanto, nem todos os moradores "contribuíam" para a realização destes serviços e muitas foram as reclamações por parte dos profissionais de saúde de "gente inculta" - moradores que se ausentavam de suas residências quando sabiam antecipadamente da visita domiciliária. Muitas eram as dificuldades apontadas, a principal delas exatamente pela falta de pessoal destinado a atuar como "inspector sanitário" e/ou "mata-mosquitos", ou seja, o autor fala em "[...] insufficiencia de pessoal em face da enormidade do trabalho a executar e premência da situação" (FRAGA, 1930, s/p).

Todo o "pessoal" (citado pelo autor) era treinado nos chamados "cursos de emergência" realizados nas sedes das seções dos distritos em todo o país. Estes cursos de emergência foram transformados em Escolas Technicas, à medida que os surtos entravam em declínio, e era possível uma organização mais acurada e menos emergente do serviço. Este se tornava de prevenção e não de desinfecção dos contagiados como ocorria durante o período de maior duração do surto. As Escolas Technicas eram dotadas "[...] do indispensável: carteiras, quadro-negro, desenhos, pinturas, toda espécie de material e objetos peculiares à policia de fócos, em tamanho natural ou em miniatura, além de apparelho para projecções fixas e animadas" (FRAGA, 1930, p. 278).

Dentre os assuntos abordados em seu "programma-summario", alguns demonstram a intenção de uma ação direta sobre o espaço geográfico. Ação esta que seria de vigilância intensa e policiamento com base no controle das populações que eram consideradas como "focos", a "classe perigosa" e dos espaços por ela habitados. As aulas práticas e "escritas" eram dadas por monitores para cada assunto. As práticas se dividiriam entre os seguintes tópicos: "[...] calhas, cemitérios, escripta, mosquitos, nebulização de insecticidas e peixes, policia de fócos, ralos, roçagem e valas"; já as escritas seriam destinadas ao preenchimento do boletim de serviços composto por "[...] cadastro dos districtos; boletim de ocorrência de irregularidades" e ainda a espacialização dos registros dos focos em mapas, os quais deveriam ser encaminhados à seção de estatística. A duração do curso seria de 15 a 18 dias, e durante o primeiro semestre de existência, ou seja, entre março e setembro de 1930 formou, apenas na capital do Rio de Janeiro, número equivalente a 662 alunos (FRAGA, 1930).

Ademais deste serviço teórico, há uma descrição em "anexo" que traz o programa de ensino das Escolas Sanitárias em um tópico intitulado: "Parte Supplementar". Nesta parte, o que mais chama atenção é a o primeiro módulo de ensino, intitulado: "Educação e propaganda sanitária". Neste módulo, caberia ao monitor discutir a necessidade da educação sanitária e a "[...] utilização dos guardas de policia de fócos na educação e propagandas sanitárias” (FRAGA, 1930, p. 287). O tópico XX também interessa diretamente por tratar mais uma vez do trato com o espaço geográfico 
DOI: $10.12957 /$ teias.\%Y.49321

das cidades e do controle sobre as habitações ao apontar: “[...] noções especiaes de hygiene: a) Hygiene da habitação; b) Hygiene individual - hábitos de hygiene - educação physica - o exame médico periódico e o exame médico pré-nupcial; c) Hygiene alimentar" (FRAGA, 1930, p. 288). O programa de ensino, o anexo e o tópico XX demonstram uma vigilância intensa e o policiamento para o controle das populações consideradas como "focos de contágio" e ainda dos espaços por elas habitados. Por outro lado, as matérias demonstram bem que a Saúde e o trato com o espaço urbano estavam relacionados a um objetivo comum: a cura das doenças e a prevenção contra as epidemias.

Esta obra trata do início da década de 1930, particularmente das campanhas em torno da febre amarela. Sua leitura nos parece ilustrativa no que se refere ao serviço de saúde pública no decorrer da década de 1920 em resposta a problemas de ordem prática, ou seja, a ocorrência de doenças, mas também de ordem ideológica e que culminará com a Criação do Ministério da Saúde na década de 1930.

Verifica-se, pois, que o processo de convencimento de grande parcela da população no tocante às necessidades do ideário higienista costumava ser difícil e lento em todo território nacional. No que se refere a Parahyba, observa-se que, em mensagem aos membros da Assembléia Legislativa da Parahyba, o, então, Presidente do Estado, Francisco Camillo de Hollanda afirmava:

Se no inverno são frequentes os casos de gripe e de outras infecções respiratórias, no verão irrompem com grande virulencia as bexigas, as febres de máu caracter e malarias em geral (...). A falta de aceitação docil da vaccina de Jenner por escrupulos mal entendidos e prejuizos inexplicaveis é a causa efficiente da terrivel propapgação das variolas, quasi proscriptas nos centros humanos, onde se pratica aquelle processo de immunidade artificial. As outras causas de mortandade encontram-se, certamente, nos defeitos architectonicos dos nossos domicilios, na ignorancia hygienica do povo e, especialmente, na falta de uma rêde de exgottos indispensavel ao asseio da cidade e da mesma população (PARAHYBA, 1917, p. 10).

Daí a importância do ambiente escolar e de meios panfletários de divulgação para que o debate se tornasse mais profícuo, no sentido de promover uma ideia que se impusesse tanto na teoria, a partir da escola, dos jornais e dos livros didáticos, como também na prática, por meio de propostas de remodelação do espaço, das intervenções diretas e da implantação de diferentes equipamentos de cunho higiênico-sanitário na cidade.

\section{DISCURSO HIGIENISTA E EDUCAÇÃO ESCOLAR NA CIDADE DA PARAHYBA}

Se o Movimento Higienista tinha como alvo basilar o combate às epidemias por meio de ações consideradas capazes de tornar as cidades mais salubres e higiênicas ${ }^{1}$, sabe-se que tal atuação não se restringia apenas ao âmbito da ciência médica, pois afetava também o cotidiano e o espaço urbano dos habitantes da cidade, visto que uma série de posturas, normas e regulamentos passaram a ser impostos à população, de modo geral. Segundo Kulesza (2010, p. 11), “[...] o processo de reajustamento urbano, imposto pela nova ótica disciplinar republicana, reivindicava uma cidade moderna".

\footnotetext{
1 Sobre o Movimento Higienista, conferir, entre outros, Rocha (2003); Barreto (2010); Sá (2009); Mariano (2015); Soares Júnior (2015); Rocha (2016).
} 
Isto se fazia importante para parte dos moradores da cidade não apenas por estarem ávidos em desfrutar das benesses da modernidade, mas também para serem reconhecidos por quem de direito como parte integrante deste novo tempo:

\begin{abstract}
Alem das informações de caracter geral, destinadas a esclarecer o espirito europeu sobre o progresso do Estado _ seu adiantamento moral, justiça, instrucção publica, cultura, hygiene, etc., o encarregado da propaganda concentrará particularmente o seu esforço na divulgação da salubridade do nosso clima. (JORNAL A UNIÃO, 14 de janeiro de 1912).
\end{abstract}

Percebe-se, portanto, que, atrelado às mudanças práticas estabelecidas no espaço urbano, havia um caráter ideológico, verificável na divulgação de hábitos higiênicos, realizada por diversos meios, dentre os quais, se destaca a educação escolar. De fato, a escola, entendida como símbolo civilizatório, "instrumento de correção" e "[...] força do progresso da sociedade brasileira" (BARRETO, 2010, p. 62) é importante elemento para divulgação do ideal higienista. Kulesza (2010, p. 11) lembra que:

A atualização formal do sistema escolar deu-se simultaneamente à introdução de
modernos equipamentos urbanos, onde as reformas urbanas constituiriam uma
forma de apropriar a paisagem ao progresso e prender-se aos princípios fixados
pelos educadores escolanovistas que postularam, alguns anos depois, uma
preocupação em não isolar a educação da vida comunitária.

Ações neste sentido vinham sendo tomadas desde meados do século XIX, mas, na Parahyba, tiveram uma ressonância maior no período da Primeira República. Um ano após a criação da primeira Diretoria de Instrução Pública (1848), houve a divulgação de um Regulamento com orientações de natureza higienista. Com isso, “[...] incorporaram-se às políticas educacionais os princípios doutrinários da higiene tanto nos aspectos normativos da organização escolar, quanto no aspecto pedagógico para a formação sanitária e moral da população" (BARRETO, 2010, p. 59). A criação de cadeiras específicas de higiene e, mais ainda, a incorporação do debate higiênico na escola, estava presente nos discursos dos intelectuais através de uma verdadeira pedagogia da higiene "[...] voltada para a formação científica e moral do cidadão e, transpondo para o universo escolar, os saberes considerados essenciais para a educação do homem dito civilizado" (BARRETO, 2010, p. 62).

O Decreto n. 7.247, de 19 de abril de 1879, incluiu a Higiene no patamar de disciplinas a serem ofertadas pelas Escolas Normais de todo país, tornando-se assim um tópico a ser tratado especificamente pela disciplina de Fisiologia. Na Parahyba, este Decreto só veio a ser cumprido no ano de 1912, quando a cadeira de História Natural foi desmembrada e deu origem à cadeira de Higiene. Com isto "[...] os conteúdos de higiene, até então trabalhados dentro da carga horária da História Natural foram elevadas ao status de 'disciplina escolar', revelando a significância que os saberes da higiene atingiram nas primeiras décadas do século XX” (BARRETO, 2008, p. 03).

A partir da ementa desta disciplina, percebemos que, dentre os temas tratados, estão alguns que se referem à higiene privada dos habitantes da cidade, mas que também se direcionam à geografia e à maneira como deve ser entendida a higienização do meio físico-geográfico, ou seja, o espaço das cidades. São elas: "[...] condições geraes de saúde, hygiene infantil, hygiene escolar, hygiene do trabalho, hygiene urbana, noções de prophylaxia, primeiros socorros em casos de ferimentos, queimaduras, asphyxia, envenamento e hygiene do lar" (JORNAL A UNIÃO, 1925; apud. BARRETO, 2008, p. 4). Desta maneira, está enfatizado que a divulgação da higiene no 
cotidiano da população se fez por várias frentes, desde as iniciativas de educação, até as visitas domiciliárias, mas também a punição e o policiamento.

A partir de análise documental sobre a cidade da Parahyba entre as últimas décadas do século XIX e o início do século XX, percebe-se que muitas eram as solicitações e recomendações para uma maior adequação do seu espaço, a fim de diminuir a ocorrência de epidemias e promover a modernização da cidade. Esta adequação se deu a partir de intervenções práticas e objetivas a partir da implementação de equipamentos urbanos, mas também estava posta a partir de um discurso higiênico que se colocava nas escolas, nos jornais, nos discursos médicos e sanitários divulgados em documentos de tipologias diversas.

Álvaro de Carvalho, diretor do Lyceu Paraibano (1916 - 1920) e secretário geral do estado (1920 - 1924), apontava, em relatório, a urgência em solidificar os princípios de higiene e saúde no ambiente escolar dentro dos parâmetros pedagógicos modernos, conforme as necessidades específicas das áreas mais vulneráveis da cidade:

Um problema, porém, domina os demais: - é a saúde e o vigor physico dos alumnos. Para a solução desejada, faz-se preciso promover a ampliação e efficiencia do serviço medico já existente, no regulamento actual; a cultura phyica tão descurada, entre nós, senão mesmo abandonada nas escolas primarias, nas normaes e no Lyceu, e a instituição da sôpa escolar ou cousa equivalente, pelo menos, nos estabelecimentos dos bairros pobres da cidade. (apud Mensagem do Presidente do Estado da Paraíba João Suassuna aos Membros da Assembleia Legislativa, JORNAL UNIÃO, 1925).

Foram tomadas uma série de medidas para que a Cidade da Parahyba se modernizasse. Entre 1911 e 1914, iniciaram-se o abastecimento de água, a iluminação elétrica e a circulação de bondes elétricos na cidade. Além disso, instituições de ensino - sejam as criadas anteriormente ou no decorrer deste período ocupavam cada vez mais o lugar de símbolos do progresso, evidenciando a modernização da cidade.

A Escola Normal, criada em 1884, era um dos elementos centrais tanto no processo de embelezamento do espaço urbano, como na legitimação e divulgação das práticas de higiene. Segundo Cardoso e Kulesza (2004, p. 3-4),

[...] a modernização urbana refletia-se diretamente no currículo escolar através da criação de cadeiras especiais. Já em 1912, seguindo o estabelecimento de um Serviço de Higiene no Estado, era criada na Escola Normal uma cadeira de higiene escolar. No regulamento de 1917 , em seu artigo $7^{\circ}$, fica bem evidenciado o utilitarismo dessa disciplina para a vida urbana em franca expansão no período: "A hygiene escolar compreenderá, além dos princípios essenciaes de hygiene geral, as noções necessarias à conservação da saúde nas escolas, e as circunstancias dependentes do meio escolar, como a localização, praticas pedagogicas, exercicios, perigos eventuais e preservação contra as molestias transmissiveis. Serão ministradas noções de puericultura, conhecimentos perfunctorios das principaes deoenças infantis para reconhecel-as e prestar os primeiros cuidados em caso de necessidade" (PARAHYBA, Decreto n. ${ }^{\circ} 873$ de 21 de dezembro de 1917).

Ao mesmo tempo em que as reformas urbanas foram responsáveis pelas iniciativas de higiene e de modernização nas ruas e nas escolas, também era o discurso escolar um dos principais responsáveis pela introjeção desses valores e práticas. Neste "processo civilizatório", o 
estabelecimento de disciplinas com temas relacionados à higiene nas escolas e a divulgação de panfletos educativos à população por meio de jornais veiculados na cidade fez-se meio para a moralidade e civilidade. Para que o "processo civilizatório" ocorresse, entendia-se que era necessário um maior controle do indivíduo sobre seu próprio corpo, suas ações e práticas, maior regulação (autocontrole); sem introjeção desses hábitos de higiene, as medidas de política sanitária seriam ineficientes (CARVALHO, 1997, p. 283). Deste modo, revelava-se urgente e necessária uma educação capaz de formar indivíduos convencidos da importância da higiene:

Ao se referirem à educação, colocando as escolas e os temas educacionais na órbita da medicina, os representantes dessa ciência [da higiene] procuraram definir um detalhado grupo de aspectos como, por exemplo, a localização física, a arquitetura, as rotinas escolares, (inserindo-se aí o tempo, conteúdos e horários de estudo), as vestimentas, alimentação, o recreio, o sono, os banhos e os princípios morais que deveriam ser cultivados nos colégios. Acompanhando este roteiro, seria possível ao Estado instalar escolas higienizadas porque modeladas consoante os princípios da higiene. (GONDRA, 2000, p. 80).

Verifica-se, portanto, uma nova cultura urbana construída, em parte significativa, por meio do trabalho de educadores e gestores convencidos da importância da higiene e da modernização: hábitos considerados insalubres tornavam-se proibidos e associados a um passado que não podia competir com o presente, nem, muito menos, com o futuro que a cidade perseguia. Deste modo, inclusive o público alvo das escolas passa a ser selecionado em função da adequação às novas normativas de higiene e saúde. Noticiava-se no Jornal A União, em 25 de janeiro de 1912:

O Candidato á matricula no 1o. anno deverá dirigir-se ao diretor por meio de requerimento no qual mencione, além de seu nome, o de seu pai, a sua idade, residência e naturalidade, exhibindo: certidão de aprovação nas matérias do ensino primário em exames finaes feitos no grupo escolar modelo ou nas escolas publicas da Capital; certidão do registro civil ou outro documento legal em que prove ter 14 annos de idade, no mínimo; atestado medico provando estar vacinado ou ter sido affectado de varíola, e não sofrer moléstia contagiosa ou incompatível com o magistério; conhecimento de haver pago a taxa de matricula.

A Reforma do Ensino de 1917 concedeu particular atenção às cadeiras de Higiene e de Educação Física. Publicada por Camilo de Holanda, então Presidente do Estado, a Reforma desempenhou um papel significativo na função normatizadora da Escola em relação ao discurso higienista, a ponto de criar diretrizes neste âmbito para a conduta de estudantes, professores, funcionários e inspetores. Sobre a Inspeção Sanitária das escolas do Estado, o artigo 257 da Reforma determinava:

a) A vigilância hygienica das escolas e do material, principalmente sobre o ponto de vista orthopedico;

b) A inspecção medica dos alumnos e do pessoal;

c) A prophylaxia das moléstias transmissíveis e evitáveis;

d) Instruir nos preceitos elementares de hygiene dos alumnos;

e) A direcção e fiscalização da educação physica nas escolas (PARAHYBA, 1917).

O Decreto no 1346 do Governo da Parahyba, de 2 de fevereiro de 1925, também reforçava que apenas poderiam se matricular no primeiro ano da Escola Normal quem apresentasse atestado 
médico de vacina, bem como não sofresse de doença infecto-contagiosa e não fosse portador de deficiência física incompatível com as atividades do magistério.

Era também a partir da própria arquitetura dos prédios escolares que a higiene e o moderno se mostravam na cidade, seguindo padrões estéticos e de salubridade que buscavam se diferenciar da cultura considerada defasada e associada propositalmente à era anterior à República. Em exposição apresentada ao Senador João Pereira de Castro Pinto, sobre os negócios públicos do Estado da Parahyba, queixava-se:

Não poderia deixar que continuassem as escolas da Capital instaladas em prédios alugados, sem satisfazerem condição alguma de hygiene escolar, feios no seu aspecto exterior e inadaptáveis em seus commodos internos.

Assim é que o governo tem em vista a construcção de prédios dignos, com ar e luz, obedecendo às regras de hygiene escolar.

Hontem, por ocasião do expediente presidencial, o ilustre sr. Dr. Matheus de Oliveira se verifica que, em futuro bem próximo, as escolas primarias da Capital vão ser dotadas de installações amplas e apropriadas ao delicado fim se instruir a infância. (JORNAL A UNIÃO, em 22 de Outubro de 1912.)

A preocupação com a salubridade do ambiente escolar despertou esforços por parte do Governo para adequá-lo (pelo menos nas escolas referência) às necessidades não apenas no que se refere à saúde e à higiene, mas também à estética, "[...] despertando na criança uma modelação dos sentidos" (SOARES Jr., 2015, p. 87). Sobre o edifício da Escola Normal, o parecer da Comissão para avaliá-la dá-nos importantes dicas sobre o que se considerava naquele período como um ambiente escolar conveniente. A Comissão era composta pelo engenheiro Matheus de Oliveira, arquitetos Hermenegildo Di Lascio e Pascoal Fiorilli, José de Azevedo Maia, inspetor sanitário escolar, e José Fructuoso Dantas, professor de pedagogia deste estabelecimento. Segue o parecer:

Todo o edifício está, a rigor, estylizado com a beleza e majestade do dórico moderno. Obedeceu a um plano consciencioso e artisticamente elaborado de par com a techinica. A simples visão agrada e se define, tal é a correção e boa medida de suas linhas. Não terá os excessos de ornamentação nem tão pouco a polychromia que tanto mal nos faz a vista e ao espírito, estroplondo-nos o senso esthetico; talvez, por isso, a alguém possa desagradar. (...) É bem de ver-se, elle o elaborou, não só tendo em vista dotar esta cidade de uma bella obra arquitetônica, mas de resolver com o maior critério pedagógico a disposição interior a semelhança dos melhores estabelecimentos congêneres. Assim, a futura Escola Normal será dotada de um systema de ventilação consoante as prescrições da hygiene escolar precisamente tropical. (...) O local foi acertadamente escolhido e está, parece-me, fadado a enfaixar as melhores obras, fazendo ângulo com dous lindos jardins que concorrerão grandemente para aumentar o arejamento (JORNAL A UNIÃO, 1917).

A infância era, muitas vezes, entendida como a fase chave para que cuidados de higiene e saúde fossem naturalizados pelos futuros cidadãos. De acordo com o médico Renato Kehl, a criança seria "boa de doutrina" (apud. BARRETO, 2010, p. 82) e cabia aos educadores fazer bom uso disto:

É das mãos do professor que sáem disciplinadas e cheias de vida, com uma orientação uniforme e constante, essas inúmeras unidades sociais, solicitadas pelos mesmos sentimentos, animadas pelos mesmos pensamentos, pelas mesmas 
ideias e pelas mesmas crenças fundidas todas nessa grande entidade social e politica que se chama - a Nacionalidade. (KEHL, 1925, p. 10).

Desta forma, livros didáticos com este objetivo - geralmente, escritos por médicos - foram lançados e adotados por escolas de vários estados. Destinado ao ensino primário, "A Fada Higia: primeiro livro de higiene" (1925), de autoria do médico Renato Ferraz Kehl, reconhecidamente eugenista, defensor da "[...] ideia de que a medicina, pela higiene, era a única promotora da evolução do corpo e da mente humana" (BARRETO, 2010, p. 80), foi uma das obras adotadas pela Diretoria Geral de Instrução Pública, inclusive na Parahyba:

A publicação no ano de 1925 de $A$ fada Higia, foi considerada por Carneiro Leão "um belo serviço prestado ao Brasil", recomendado por Belisário Penna como "atenta e repetida leitura das crianças desse livrinho", as melhores "noções de higiene, tomando por base o ensino e a pedagogia" e a "estima dos brasileiros ao conhecido médico que luta pelo melhoramento e prolongamento da vida", afirmou Osório Duque Estrada; e a adoção de um "bom sistema de educação dos pequenos e grandes, um attestado valioso da vitória da propaganda da consciência sanitária que redimirá os paraibanos do opróbrio", escreveu Flávio Maroja, importante e renomado médico higienista paraibano e os demais educadores acima citados nas considerações finais do livro - A Fada Higia". (ROCHA, 2016, p. 77).

O livro, a ser utilizado por professoras do ensino primário nas matérias de higiene e de educação física, continha noções de higienização do corpo, destacando a necessidade do asseio dos corpos, mas também a salubridade do espaço urbano, enfatizando a importância da limpeza das moradias, das ruas e dos terrenos não construídos (ROCHA, 2016, p. 79).

\section{CONSIDERAÇÕES FINAIS}

A partir da análise bibliográfica e documental utilizada para a construção desta pesquisa, percebe-se que a educação da população pela obtenção de hábitos higiênicos se daria, entre outros meios, a partir da criação de cadeiras de higiene nas escolas ou ainda das campanhas de educação higiênico-sanitárias que eram divulgadas através da imprensa e dos folhetos educativos e de um aparato científico-policial voltado para prescrever regras e fiscalizar as populações. Neste sentido, a relação entre educação e higiene estaria relacionada à promoção de hábitos ligados a um cotidiano higiênico e salubre, temas que ademais da moral e do progresso aparecem nos documentos oficiais.

As campanhas educativas, ademais das cadeiras de higiene, foram aqui destacadas porque representam muito da política sanitária e de visitas domiciliares que se deram a partir deste momento e que persistiram por décadas. Desta forma, a educação e a divulgação de hábitos higiênicos se fazem presentes nas escolas, nos anúncios de jornais e em panfletos educativos criados e difundidos pelo Estado.

No entanto, sabemos que nem tudo se tratava de campanha educativa, na verdade, percebemos, a partir das publicações tanto dos periódicos, como ainda dos documentos oficiais, que havia um tratamento policialesco à vacina e às normas de higiene (como exemplo, temos a proibição dos banhos nas fontes públicas; a vacinação; a recomendação para a instalações domiciliárias de água; o estabelecimento de prazos para limpeza de quintais). 
Estas medidas faziam parte, portanto, das normas que compunham a adequação da cidade às características de urbe moderna. Sendo assim, uma cidade seria considerada moderna se, e somente se, estivesse adequada a padrões de salubridade. Mas, embora este seja um elemento importante, também não é isolado ou único. Para ser considerada moderna a cidade deveria ser habitada por uma população também moderna: limpa, civilizada e sã.

Isso nos leva a crer que os projetos de Modernidade e Sanitarismo inferem diretamente nos hábitos de uma população que nem sempre está afeita a receber tais padrões. Daí a necessidade de prepará-los para receber tal Modernidade através de panfletos, campanhas educativas, disciplinas escolares, divulgação em jornais de circulação diária e, como vimos, uma série de medidas educativas.

\section{REFERÊNCIAS}

ABREU, Maurício de. Sobre a memória das cidades. Revista da Faculdade de Letras/ Geografia. I Série, vol. XIV. Porto, 1988.

ABREU, Maurício de. Cidade brasileira: 1870-1930. In: SPOSITO, Maria Encarnação Beltrão. (org.). Urbanizaçãa e cidades: perspectivas geográficas. GASPERR, Presidente Prudente: UNESP, 2001. Disponível em

$\leq$ http://observatoriogeograficoamericalatina.org.mx/egal8/Geografiasocioeconomica/Geografi aurbana/62.pdf $>$. Acesso em dez. 2013.

BARRETO, Aparecida de Lourdes Paes. Pedagogia da Higiene na Paraíba: Saberes que circulavam nos livros escolares. In: Anais do V Congresso Brasileiro de História da educação. UFSE: Aracaju, 2008.

BARRETO, Aparecida de Lourdes Paes. Higienismo e Educação na Paraíba. In: CARDOSO, Carlos Augusto de Amorim; KULESZA, Wojciech Andrzej. A Escola e a Igreja nas ruas da cidade. João Pessoa: Editora Universitária UFPB, 2010.

CARDOSO, Carlos Augusto de Amorim; KULESZA, Wojciech Andrzej. Escola e Modernidade na Paraíba (1910-1930). In: Anais do 3o. Seminário Brasileiro de História da Educação. 2008. Disponível em http://sbhe.org.br/novo/congressos/cbhe3/Documentos/Coord/Eixo4/490.pdf. Acesso em 27 jan. 2021.

CARvalHO, Antonio Ivo de. Conselhos de saúde, responsabilidade pública e cidadania: a reforma sanitária como reforma do estado. In: FLEURY, Sonia. Saúde e democracia: a luta do CEBES. São Paulo: Lemos, 1997.

COSTA, Emília Viotti da. Da monarquia à república: momentos decisivos. São Paulo: fundação Editora da UNESP, 1999.

FRAGA, Prof. Clementino. A febre Amarella no Brasil: Notas e documentos de uma grande campanha sanitária. Rio de Janeiro: Off. Graph. De Imp. De Demographia Sanitária, 1930.

GONDRA, José Gonçalves. Artes de Civilizar: medicina, higiene e educação escolar na Corte Imperial. Tese (Doutorado em Educação), Universidade de São Paulo, São Paulo, mar. 2000.

GREGORY. D. J. La acción de la estructura de la geografía histórica. In: CORTEZ, Claude. Geografía Histórica. Ed. México: Instituto de Investigaciones Dr. José María Luis Mora, 1991.

KULESZA, Wojciech Andrzej. Introdução. In: CARDOSO, Carlos Augusto de Amorim e KULESZA, Wojciech Andrzej. A Escola e a Igreja nas ruas da cidade. João Pessoa: Editora Universitária UFPB, 2010. 
KEHL, Renato. A fada hygia: primeiro livro de hygiene. Rio de Janeiro: Francisco Alves, 1925.

JORNAL A UNIÃO. Acervo (físico) do Arquivo do Maurílio de Almeida, situado em João PessoaPB. Disponível em Banco de Dados do GeUrb (UFPB).

LE GOFF. Jacques. História e memória; tradução Bernardo Leitão. $3^{\mathrm{a}}$ ed. Campinas, SP: Editora da Unicamp, 1996.

MACHADO, Roberto; LOUREIRO, Angela; LUZ, Rogerio; MURICY, Katia. Danação da norma: Medicina Social e constituição da psiquiatria no Brasil. Rio de Janeiro: Editora Graal, 1978.

MARIANO, Nayana Rodrigues Cordeiro. Educaşão pela higiene: a invenção de um modelo hígido de educação escolar primária na Parahyba do Norte (1849-1886), 2015. 254 f. Tese (Doutorado em Educação), Universidade Federal da Paraíba, João Pessoa, 2015.

MASTROMAURO, Giovana Carla. Surtos epidêmicos, teoria miasmática e teoria bacteriológica: instrumentos de intervenção nos comportamentos dos habitantes da cidade do século XIX e início do XX. Anais do XXVI Simpósio Nacional de História - ANPUH. São Paulo, jul. 2011. Disponível em

http://www.snh2011.anpuh.org/resources/anais/14/1300472386 ARQUIVO Mastromauro.pd f. Acesso em 10 jul. de 2018.

NAGLE, Jorge. Educação e sociedade na Primeira República. Rio de Janeiro: DP\&A, 2001 [1974].

NORA, Pierre. Entre mémoire et et histoire. In. (org.). Les lieux de mémoire. vol. I. La République. Paris: Gallimard, 1984.

PARAHYBA. Decreto no 873, de 21 de dezembro de 1917. Regulamento da instrucção primaria do estado. Imprensa Official - Parahyba, 1927.

PHILO. Chris. História, geografia e o "mistério ainda maior" da geografia histórica. In: GREGORY. Dereck et al. (org.) Geografia bumana: Sociedade, espaço e ciência social. Rio de Janeiro: Jorge Zahar Editora, 1996.

ROCHA, Heloísa H. Pimenta. A bigienização dos costumes: educação escolar e saúde no projeto do Instituto de Higiene de São Paulo (1918-1925). Mercado das Letras. São Paulo: Fapesp, 2003.

ROCHA, Francineide R. P. A oficina da nacionalidade: higienização das crianças e das mães na Parahyba (1911 a 1927). Dissertação (Mestrado em Educação), Universidade Federal da Paraíba, João Pessoa, 2016.

SÁ, Nirvana L. A. Rafael. de. A cidade no despertar da era higiênica. O Movimento Higienista na Cidade da Parahyba entre 1854 - 1912. Dissertação (Mestrado em Geografia), Universidade Federal da Paraíba, João Pessoa, 2009.

SOARES JÚNIOR, Azemar dos Santos. Physicamente vigorosos: medicalização escolar e modelação dos corpos na Paraíba (1913-1942). 2015. 271 f. Tese (Doutorado em Educação), Universidade Federal da Paraíba, João Pessoa, 2015.

URTEAGA. Luis. Miseria, miasmas y microbios. Las topografías médicas y el estudio del médio ambiente en el siglo XIX. Revista Geo Crítica, set. 1980. 


\section{Informações dos autores}

Carlos Augusto de Amorim Cardoso DME/PPGH/UFPB

E-mail: caugusto@ce.ufpb.br

ORCID: https://orcid.org/0000-0002-1070-5608

Link Lattes: http://lattes.cnpq.br/9003023654793814

Eliana Alda de Freitas Calado

PNPD/Capes - PPGH/UFPB

E-mail: elianacalado@gmail.com

ORCID: https://orcid.org/0000-0002-1241-3828

Link Lattes: http://lattes.cnpq.br/4802571462567786

Nirvana Lígia Albino Rafael de Sá

PNPD/Capes - PPGH/UFPB

E-mail: nirvanadesa@gmail.com

ORCID: https://orcid.org/0000-0002-3932-1026

Link Lattes: http://lattes.cnpq.br/1072808055316794 